\title{
Atividades físicas, saúde e movimentos juvenis em Cabo Verde, 1910-1930
}

\section{Physical activities, health and youth movements in Cape Verde, 1910-1930}

Victor Andrade de Melo

Professor do Programa de Pós-graduação em História Comparada, Instituto de Filosofia e Ciências Sociais/ Universidade Federal do Rio de Janeiro.

Largo de São Francisco, 1, sala 311

200051-070 - Rio de Janeiro - RJ - Brasil

victor.a.melo@uol.com.br

MELO, Victor Andrade de. Atividades físicas, saúde e movimentos juvenis em Cabo Verde, 1910-1930. História, Ciências, Saúde - Manguinhos, Rio de Janeiro, v.19, n.3, jul.-set. 2012, p.843-860.

\section{Resumo}

Discute as relações entre as preocupações com a saúde, o estímulo à prática de atividades físicas e a organização de movimentos juvenis em Cabo Verde nas décadas de 1910-1930.

Esse arquipélago constitui um entroncamento de rotas navais, pelo desenvolvimento precoce de comportamentos modernos e pela relação peculiar com Portugal, marcada pela construção de uma identidade própria (a cabo-verdianidade), cuja reivindicação básica não reside na autonomia jurídica, e sim em seu pleno reconhecimento como parte do 'glorioso Império português'. Foram analisados relatos de viajantes, documentos de arquivos, depoimentos, livros de memorialistas e periódicos.

Palavras-chave: saúde; ginástica; esporte; juventude; Cabo Verde.

\section{Abstract}

This paper discusses the relationship between health concerns, encouraging the practice of physical activities and the organization of youth movements in Cape Verde during the decades of 1910-1930. This archipelago is a junction of naval routes, by its precocious development of modern behavior and by its peculiar relationship with Portugal, marked by the construction of its own identity (CapeVerdeanness), whose basic claim lies not in legal autonomy, but in its full recognition as part of the 'glorious Portuguese Empire.' Reports of travelers, archival documents, depositions, books of memoirs and journals were analyzed for this research.

Keywords: health; gymnastics; sport; youth; Cape Verde. 
$\mathrm{E}$ m Cabo Verde, arquipélago localizado na costa oeste da África, colônia de Portugal até 1975, em função de uma série de particularidades históricas - especialmente aquelas relativas às condições de seu 'achamento' (colonização das ilhas desabitadas por povos de fora) e à falta de um controle rígido por parte da metrópole - percebe-se, desde o século XVIII, a conformação de uma elite nativa constituída por mestiços (Silva, Cohen, 2003). No caso cabo-verdiano, em particular: "A crioulização abre portas para que determinados segmentos populacionais comecem a presumir-se detentores dos atributos antes reconhecíveis apenas aos grupos de maior prestígio e poder e a exigir um tratamento consentâneo com essa condição" (Fernandes, 2006, p.69).

Os cabo-verdianos aprenderam a lidar com a dubiedade colonial de Portugal, que sobrepunha as noções de império e nação, por conta da necessidade de manutenção dos seus territórios na África, da peculiaridade de seu desenvolvimento econômico (a colonização portuguesa não sendo fruto da industrialização) e mesmo de sua trajetória histórica e características geográficas, estando o país espremido entre a Espanha e o mar.

Como afirma Pimenta (2010, p.21): "O nacionalismo português teve uma expressão sobretudo colonial, no sentido de que procurou o seu fundamento na expansão colonial e na conquista de um novo Império em África". Foi a partir das brechas e contradições dessa compreensão - o império como nação - que Cabo Verde foi - se constituindo uma protonação com aspirações modernas no meio do Atlântico.

Na transição entre os séculos XIX e XX, a elite cabo-verdiana passou por mudanças: reduziu-se o poder dos donos de terra, tanto em função do agravamento dos problemas agrários quanto de uma maior presença do governo metropolitano, dado o incremento da expansão colonial. Nesse cenário, ganhou força uma intelectualidade nativa que, mais do que se apresentar, passou a ser efetivamente reconhecida como interlocutora/ mediadora. Mesmo quando, em alguns momentos da história, devido a desdobramentos das mudanças no quadro político de Portugal, o poder e a influência desse grupo viram-se diminuídos, ele permaneceu ativo e ainda mais disposto a reivindicar respeito ao arquipélago, implementando estratégias emancipatórias que marcaram definitivamente as relações entre a metrópole e a colônia.

Nesse quadro, notadamente a partir da transição do século XIX para o XX, a adesão a certas práticas relacionava-se a um conjunto de iniciativas que visava subverter a consideração do colonizador de que o nativo era "alguém menor". Civilizado que era - em certa medida, reconhecido pela própria metrópole, que concedia ao arquipélago algumas exceções no relacionamento colonial -, o nativo podia exigir um tratamento diferenciado, o respeito às peculiaridades locais.

Demonstrar hábitos modernos, entre os quais a valorização das atividades físicas e dos cuidados com a saúde, a higiene e o corpo, reforçava a ideia recorrente de que Cabo Verde era uma colônia distinta, sintonizada com os 'progressos' mundiais. Esse tipo de estratégia consistia em: "Uma luta não propriamente contra a soberania nacional, mas contra o trato colonial. Ou seja, [os cabo-verdianos] aceitam os pressupostos nacionalizantes, mas propugnam a eliminação dos marcos diferenciais legitimadores das práticas coloniais" (Fernandes, 2006, p.42). Esse diálogo com referências exteriores, segundo Anjos (2006, p.25), parece ter sido uma linha de ação comum na história do arquipélago: 
a classe política cabo-verdiana, inclusive nos momentos de contestação, recorre a paradigmas e modelos estrangeiros para criar ação mobilizadora. A negação dos modelos estrangeiros é sempre parcial e dada pela importação de outros modelos também estrangeiros.

Essas práticas modernas, notadamente as atividades físicas, estruturaram-se pioneiramente em Mindelo, a capital de São Vicente, ilha que, desde o último quartel do século XIX, exibia mais vitalidade cultural em função de um sistema educacional organizado, uma imprensa vibrante, a atuação de intelectuais notáveis e sua sintonia com o restante do mundo, dado o intenso movimento verificado em seu porto, o Porto Grande, na baía de Mindelo.

No decorrer do século XIX, com a expansão do comércio internacional que fazia uso de navios a vapor, tornou-se necessário estabelecer entrepostos para abastecimento de carvão. Na baía de Mindelo, localizada no cruzamento de várias rotas navais importantes e com boas condições para receber embarcações de maior porte, foram instalados depósitos de companhias de capital inglês. Assim, naquele fin de siècle: "Quase todos os fluxos de mercadorias e de homens, quase todos os circuitos de comunicação ..., em suma, quase tudo o que atravessa o imenso Atlântico está condenado a utilizar a ilha de S. Vicente e o seu Porto Grande" (Silva, 2000, p.16).

A instalação de infraestrutura adequada à nova movimentação comercial alterou significativamente a paisagem de Mindelo. Marília Barros (2008) lembra que a cidade se tornou o principal centro urbano da colônia, grande motor da economia do arquipélago. Por lá, foram gestadas tanto uma burguesia local menos dependente da metrópole quanto uma classe trabalhadora com características mais próximas às de um operariado; em linhas gerais, tratava-se de uma sociedade civil mais ativa e participante.

Diante dessas circunstâncias, São Vicente passou a atrair muita gente: de outras ilhas de Cabo Verde, da metrópole e de outros países, não só populares mas também pessoas de estratos socioeconômicos mais altos, todos em busca de trabalho e/ou de novas oportunidades de negócios. Mais ainda, conforme destaca Silva (2000, p.130): "Além da comunidade estrangeira residente, a cidade é permanentemente inundada pelo frenesi constante daqueles que chegam e partem no espaço de tempo apenas necessário ao reabastecimento dos vapores". ${ }^{1}$

Para empregar a bela expressão cunhada por Silva (2000), a cidade transforma-se em um 'onívoro cultural', digerindo tudo o que chega pelo porto, inclusive as práticas de diversão, que começam a se configurar como uma peculiaridade local. A população do Mindelo torna-se cada vez mais conhecida por ser apreciadora de festas, e o município, pela agitação dos bares e das atividades públicas. Obviamente, como nos lembra Silva (2000, p.133): "No Mindelo, como alhures, o lazer não anula por completo as fronteiras sociais. As elites locais criam seus espaços reservados de diversão com a preocupação evidente de se demarcar do povo".

Na verdade, a despeito da efetiva possibilidade de ascensão social, não era nada fácil a vida dos populares, sobretudo dos que trabalhavam diretamente nos depósitos de carvão: má alimentação, habitação deficiente, problemas com a saúde, muitos decorrentes da 
própria atividade (doenças pulmonares, por exemplo) ou mesmo da dinâmica de uma cidade portuária (doenças venéreas). Também eram péssimos, em geral, os salários.

De qualquer forma, interessa ter em mente a visão de Mesquitela Lima (1992) sobre a sociedade mindelense naquele momento. Segundo o autor, havia uma elite formada por mestiços e brancos que atuavam como professores, advogados, comerciantes e funcionários públicos de alto escalão, bem como por estrangeiros que dirigiam empresas de capital europeu; uma camada média, formada por pequenos comerciantes, empregados de algumas firmas e certos funcionários públicos; e os populares, trabalhadores em geral. O mais interessante é que o autor identifica certa porosidade entre os três estratos, o que ajuda a compreender que

A maior parte dos mindelenses, mesmo o menos dotado, tem o culto da cultura, conhece seus poetas e escritores, cita os seus nomes, possivelmente sem os ter lido. Nos bailes nacionais de Bia de Djaco ou de João de Tolentino, há indivíduos que fazem discursos com pretensões eruditas, o mesmo sucedendo em certos clubes populares como o Castilho, Derby e Amarante (p.37).

Considerando tal quadro, o presente estudo objetiva discutir as relações entre as preocupações com a saúde, o estímulo à prática de atividades físicas e a organização de movimentos juvenis em Cabo Verde (décadas de 1910-1930), arquipélago caracterizado por constituir um entroncamento de rotas navais, pelo desenvolvimento de comportamentos modernos, desde as décadas finais do século XIX, e pela relação peculiar estabelecida com a metrópole, marcada pela construção de uma identidade própria (a cabo-verdianidade), cuja reivindicação básica não reside na autonomia jurídica, e sim em seu pleno reconhecimento como parte do 'glorioso Império português'.

Para tanto, foram analisados relatos de viajantes (como o de Acher, 1950), documentos de arquivos (como o Estatuto, 1934), depoimentos (como os constantes em Lopes, 2002), livros de memorialistas (como o de Ramos, 2003) e periódicos (Independente, O Futuro de Cabo Verde, Notícias de Cabo Verde, Eco de Cabo Verde, Boletim dos Falcões de Cabo Verde, A Mocidade, Arquipélago).

É interessante observar que tanto as preocupações com a saúde quanto o estímulo à prática de atividades físicas já constavam de algum modo na pauta das lideranças intelectuais de Cabo Verde desde o século XIX. Por exemplo, naquele momento, eram comuns atividades como conferências e cursos sobre higiene popular, promovidos, no Teatro Africano, pelo militar e médico Francisco Frederico Hopffer, importante personagem da história caboverdiana. $^{2}$

Em 1904, foi fundada a primeira agremiação cabo-verdiana a conceder mais atenção às atividades físicas: o Club Mindelo. Mesmo se apresentando como uma "associação literária e de instrução", os seus estatutos previam no artigo 2: "proporcionar o desenvolvimento físico por meio da ginástica" (Oliveira, 1998, p. 42). Tratava-se claramente de uma influência dos europeus que habitavam a região do Mindelo e/ou que atracavam em seu movimentado porto. Lembremos que, no século XIX, a prática já era incentivada em muitos países, entre os quais a Suécia, a Dinamarca, a França e a Alemanha. ${ }^{3}$

Devemos considerar ainda as ações do relevante Liceu Infante D. Henrique, de Mindelo que, criado em 1917, previa desde o início a obrigatoriedade da disciplina 'ciências físicas, 
naturais, higiene e educação física'. Muitos de seus professores envolveram-se em iniciativas ligadas a preocupações com a saúde da população. Por exemplo, Adriano Duarte Silva (1924) chamava a atenção para a necessidade de maior valorização das atividades físicas, a seu ver de grande importância para o 'aperfeiçoamento da raça' e para a educação da juventude. De acordo com sua perspectiva, os exercícios constituiriam um aspecto fundamental para um projeto pedagógico mais atualizado, atraente e completo.

Outro indicador importante foi o paulatino crescimento do número de artigos publicados nos periódicos locais que tinham como tema central a questão da saúde, não poucas vezes relacionando-a à prática de exercícios físicos. Um exemplo é o de Augusto Miranda (11 ago. 1933) que tinha em mente o grande número de problemas com os quais a população de Mindelo sempre convivera, mas dialogando igualmente com experiências internacionais:

A saúde pública liga-se, portanto, com os assuntos principais da administração do Estado ... Assim, o reconheceram os estadistas do Brasil, não poupando a sua nação as despesas enormes para sanear sua grande capital. O aformosamento do Rio de Janeiro resultou das obras importantes ali realizadas a maior riqueza pública, consequente do aumento do vigor físico da população.

Essa preocupação com a saúde das colônias não era incomum desde o final do século XIX, quando cresceram as iniciativas portuguesas de melhor ocupar e controlar seus territórios na África. ${ }^{4}$ Aliás, segundo conclui Iliffe (1999), tratava-se de algo observável em todo o continente africano. No caso cabo-verdiano, percebe-se uma boa acolhida dessas iniciativas e até mesmo constantes reivindicações de maior ação por parte da metrópole.

Nesse quadro em que aumentaram as preocupações com a saúde e o estímulo à prática de atividades físicas, dois movimentos juvenis se estruturaram em Cabo Verde nas décadas de 1910-1930. Para melhor entender o contexto social no qual se desenvolveram, tracemos um panorama da vida pública na cidade de Mindelo naquele momento.

\section{A vida pública: cinema, esporte e outras diversões}

Em Cabo Verde, as décadas de 1910 e 1930 foram marcadas por uma decepção com os caminhos da República portuguesa (iniciada em 1910), que não trouxe as esperadas mudanças para o arquipélago. Na verdade, a instabilidade de Portugal e sua incapacidade de resolver seus problemas, além do quadro contextual europeu, levaram, em 1926, à queda da Primeira República e à instauração do que foi um dos mais longos regimes autoritários da história. O impacto sobre as colônias foi bastante sensível: "A ditadura restringiu a autonomia das colônias mediante a promulgação das Bases Orgânicas da Administração Colonial" (Pimenta, 2010, p.59). Com a ascensão definitiva de António Salazar à liderança do novo regime (1933), o Estado Novo, o quadro tornar-se-ia ainda mais complicado.

Nesse cenário, em Cabo Verde, novas posturas foram entabuladas, ainda que, em linhas gerais, continuassem e aprofundassem a estratégia anterior de construção identitária. É possível afirmar que o discurso lusitano-crioulo conformou-se "Não pela via de rompimento, mas sim de reiteração da lealdade dos filhos da terra à grande Pátria lusitana. É o desejo de 
plena inclusão nacional que impulsiona a luta contra seu braço colonial" (Fernandes, 2006, p.20). Ao reivindicarem o seu reconhecimento como lusitanos de fato e de direito, os crioulos visavam daí extrair elementos para uma disputa mais equânime.

Nesse contexto, o âmbito cultural apresentou-se como um dos principais cenários de luta, lócus privilegiado para a construção de representações que se articulavam às reivindicações locais, no sentido de expressar os limites de certas construções coloniais. O momento foi marcado pela "consistência do campo cultural, testemunhada pelo protagonismo cada vez maior dos novéis filhos da terra, seja nas instituições de educação, seja nas variadas produções culturais" (Fernandes, 2006, p.112).

Na década de 1930, mesmo com os muitos problemas desencadeados por crises de abastecimento, observa-se em Mindelo uma vida pública já bem estruturada. Segundo Maria Acher (1950, p.35), de forma um pouco exagerada, mas de maneira alguma equivocada, os cabo-verdianos:

\footnotetext{
Vestem-se pelos figurinos franceses, recebem elegantemente em suas casas, compram automóveis de boa marca, viajam em primeiras classes, interessam-se por assuntos de arte e cultura. As cidades são iluminadas a eletricidade, dispõem de água canalizada, esgotos, pavimentos modernos, jardins, diversões. Muitas cidades da província, em Portugal, são mais monótonas e rotineiras do que estas. Praticam ali largamente o desporto, quer náutico, quer terrestre, com animadas competições. Brancos e crioulos frequentam os clubes de natação, remo, vela, tênis, futebol etc. Evidentemente que a bola é o desporto preferido. ${ }^{5}$
}

Depois das primeiras experiências realizadas em Praia, a capital da colônia, na primeira década do século XX, foi mesmo em Mindelo que se inaugurou o primeiro cinema de Cabo Verde, em 1919. A grande sala, que permaneceu na história do país e na memória de muitos cabo-verdianos, abriu suas portas em 1922: o Éden Park.

Como era comum em muitos países, o cinema transformou-se rapidamente em um 'salão de novidades': além da projeção de filmes, no Éden eram realizadas exibições de teatro, conferências (entre as quais as de importantes intelectuais locais, como Baltasar Lopes e os envolvidos com a revista Claridade ${ }^{6}$, reuniões políticas, atividades circenses, espetáculos musicais, bailes de carnaval, demonstrações de ginástica, entre outros eventos.

Luís Silva (2006), um dos mais ferrenhos defensores das tradições culturais de Mindelo, exalta do seguinte modo a importância do Éden, em um exercício de memória com o qual coadunam muitas lideranças da cidade:

De todas as ilhas acorriam pessoas para assistir os vários espetáculos organizados no Éden Park ... Mais do que qualquer outra escola, teve sempre preocupação de servir às classes sociais mais modestas, levando-lhes a instrução e a cultura popular. O Éden Park, graças à passagem de grandes filmes, trouxe aos cabo-verdianos os exemplos da dignidade e da solidariedade humana e ainda a consciência da liberdade. Mais ainda: também desenvolveu o nosso sentido de revolta contra as traições, o racismo, as injustiças humanas, a esperança dum mundo melhor onde a justiça estaria acima de todos e que seríamos capazes de criar uma elite que fosse o exemplo de dignidade e patriotismo para o nosso povo.

Por ocasião da Primeira Guerra Mundial, quando Portugal, a título de garantir a segurança do arquipélago, envia forças armadas para São Vicente e Santo Antão - apesar de ter declarado 
neutralidade no conflito mundial -, o cinema parece vivenciar seu momento áureo, atendendo às tropas que se instalaram em Mindelo.

Se o Éden ocupou espaço de importância, a vida festiva era certamente mais ampla. Em Mindelo, que passava por reformas urbanas e iniciativas de embelezamento, a chegada da luz elétrica em 1929 permitiu a diversificação das práticas de diversão, notadamente as noturnas. Em 1930, foi construído um edifício para o ensaio da banda municipal, foi inaugurado o Estádio da Fontinha e foram realizadas as primeiras corridas de automóveis/ gincanas automobilísticas na praia da baía das Gatas (provas essas repetidas com certa frequência). Nesse mesmo ano, foi estabelecido oficialmente o descanso semanal aos domingos.

Em São Vicente, destacava-se ainda o grande número de atividades carnavalescas, até hoje uma das marcas mais conhecidas dessa ilha. Pelos jornais, vemos as propagandas e comentários dos bailes oferecidos no Grupo Cruzeiro, no Belo Horizonte Nacional, no Flor do Oriente, no Fichismo, no Marcaridu, no New Island Star, no Flor do Atlântico, no Sousa Cruz, no Monumental, no Grêmio Caboverdiano, no Éden Park.

A vida festiva ficava ainda mais intensa quando navios estrangeiros atracavam no Porto Grande, ainda que o fluxo já não fosse igual ao que se observara no século XIX. Por exemplo, em dezembro de 1937, quando por ali aportou um encouraçado alemão, foi realizada uma série de atividades: passeio de automóvel, concerto da banda municipal, chá dançante, jogos de futebol, partidas de tênis. Os alemães, por sua vez, retribuíram a calorosa recepção com apresentações de ginástica e exibições de seu conjunto musical.

Os clubes esportivos, que já existiam em bom número, contribuíam com o ar de festividade tanto por suas atividades cotidianas quanto por suas comemorações. Bons exemplos foram os festejos do $14^{\circ}$ aniversário do Castilho (realizados em março de 1937) e a entrega de faixas à equipe de futebol do Mindelense, vencedora do campeonato de São Vicente de 1941.

Os periódicos, por sua vez, passaram com mais frequência a abrir espaço para as novidades esportivas. O Notícias de Cabo Verde, lançado em 1933, desde as primeiras edições exibia uma coluna inteiramente dedicada ao tema; em 1940, criou um suplemento de duas páginas. Essa experiência levou ao lançamento do primeiro jornal esportivo da colônia, em dezembro de 1944: o Goal. Os responsáveis por essas iniciativas foram dois importantes personagens da história do arquipélago: Evandro de Matos, o Evandrita, e Joaquim Ribeiro.

Ribeiro foi, aliás, um dos homens que melhor expressou os novos tempos marcados por uma vida pública mais intensa. De família cabo-verdiana, embora tenha nascido na Guiné, viveu parte da infância e da adolescência em São Vicente e em Portugal, tendo sido designado, quando retornou à ilha, professor de ginástica do Liceu Gil Eanes.

Jogador de futebol e atleta de diversas modalidades, Ribeiro foi membro de vários clubes, além de dirigente de federações esportivas. Envolvido com muitas iniciativas políticas e culturais, atuante em vários periódicos, ficou também conhecido por ser galanteador e namorador. Foi ainda um dos pioneiros da aviação em Cabo Verde. Tinha um perfeito physique du rôle moderno.

Diante do avanço das vivências públicas de lazer, o governo metropolitano tomou iniciativas diversas. Em algumas oportunidades, estimulou certas práticas. Por exemplo, em 1934, baixou os impostos e criou privilégios para manter abertos os teatros. As ações de 
restrição, contudo, foram em maior número: o uso dos balneários passou a ser mais bem regulamentado e as atividades musicais que tanto agradavam à população sofreram interferências significativas, especialmente em Mindelo, onde claramente se delineava uma musicalidade própria.

Obrigatoriedade de pedido de licença para a realização de bailes, aumento de impostos para a promoção dessas atividades, tentativa de acabar com a banda de música - essas decisões desencadearam uma onda de protestos dos "munícipes que se viram assim privados de um divertimento muito apreciável em terras de África. Protestamos com os munícipes de Mindelo contra tão estranha medida" ([Noticiário], 15 jul. 1933, p.1).

O Eco de Cabo Verde ecoava as críticas populares: "Por que acabar com este lenitivo do povo que aos domingos se reunia na praça para se esquecer do quadro pungente que tem em casa?" ([Noticiário], 22 dez. 1934, p.3). Para o periódico: "Estamos sob o regime de terror. Pobre povo! Não podes folgar! Não podes esquecer os teus males que são cotidianos!" ([Noticiário], 15 jul. 1933, p.7).

De um lado, uma intensa vida festiva e o estímulo à busca da excitabilidade; de outro, o excesso de trabalho para pessoas das camadas populares e as iniciativas de controle do tempo livre. Nesse quadro de ambiguidades, foram organizados dois significativos movimentos juvenis que tinham a saúde como uma de suas preocupações centrais e as atividades físicas como estratégia fundamental: o escotismo e os Falcões.

\section{O escotismo}

Nos primeiros anos da década de 1910, foi criado, em Mindelo, um grupo de escoteiros - movimento fundado, em 1907, pelo general inglês Baden Powell, a partir de suas experiências em campanhas militares na África do Sul, com o intuito de constituir uma instância de educação de jovens, ancorada em três pilares: desenvolvimento físico, desenvolvimento moral e desenvolvimento intelectual. Vale destacar que, em função de seus princípios, as atividades físicas eram encaradas como importante ferramenta, e o desenvolvimento de hábitos saudáveis considerado um de seus objetivos. ${ }^{7}$

Em muitas colônias africanas, segundo Martin (1995, p.92): “O escotismo foi visto como um excelente treino-base para formar uma elite que, por sua vez, irá exercer boa influência sobre as massas". No caso cabo-verdiano, tratava-se, fundamentalmente, de algo que tinha raízes internas, não uma imposição externa, algo que atendia estritamente, ou ao menos linearmente, aos desejos do colonizador, que sequer teve influência na fundação do grupo de Mindelo.

No arquipélago, o líder dos escoteiros foi Simão Barbosa, um dos mais notáveis educadores de Cabo Verde, figura importante da sociedade mindelense, igualmente envolvido com a criação do Liceu Infante D. Henrique. Muito rapidamente o movimento passou a ser valorizado pelas lideranças locais e a ser apoiado por iniciativas diversas, como a organização de récitas, por exemplo. Segundo informa Joaquim Saial (2006):

Ainda no mesmo ano [1913], em 7 de Novembro, houve no Mindelo uma récita a favor dos escuteiros (boy scouts), organizados por Simão Barbosa, que reverteu para o cofre dos mesmos. Cantou-se 'A Portuguesa' - acompanhada ao piano por uma miss Eveleigh, à 
rabeca por Chaluio e Correia e ao violão por Mariano e Martinho - representaram-se comédias, cantou-se a 'Sementeira', fez-se ginástica sueca.

Além das atividades de campismo, os boys scouts praticavam diariamente a ginástica. Suas exibições públicas contribuíram para torná-las apreciadas em Mindelo. Vejamos a notícia de 1913: "A ginástica sueca executada ... agradou muito, despertando admiração o fato de se não desconectarem os meninos, quando, em outras circunstâncias, poderiam assustar-se e interromper os exercícios" ([Noticiário], 20 nov. 1913, p.3).

Os rapazes chegaram a se apresentar em outras ilhas, inclusive na capital, Praia: "Principiou o espetáculo pela apresentação de um grupo de 18 alunos os quais, sob a direção do seu professor, Simão Barbosa, executaram com muita correção e uniformidade vários movimentos livres de ginástica sueca" ([Noticiário], 12 ago. 1912, p.2).

A ginástica sueca surgiu na primeira metade do século XIX, tendo como um de seus líderes Per Henrik Ling. O método notabilizou-se por sua preocupação científica, tanto no que se refere ao uso de conhecimentos da anatomia e da fisiologia quanto no tocante a preocupações de natureza pedagógica. Os exercícios eram concebidos para respeitar e contribuir para a potencialização das aptidões físicas e da saúde dos praticantes. Foi adotada em muitos países até a década de 1940, embora, na ocasião, já existissem outros métodos gímnicos.

A adesão ao método sueco é mais um dos indícios de que os boys scouts estavam plenamente inseridos no quadro sociocultural mindelense da época. Se, por um lado, eles mantinham relações com a ambiência cultural da cidade, por outro, atendiam à necessidade - sentida por algumas lideranças locais, não necessariamente ligadas ao governo metropolitano de disciplinarização e de desenvolvimento de hábitos saudáveis.

\section{Os Falcões}

Nos anos 1930, surgiu em Cabo Verde um movimento que ocupou um espaço ímpar na memória da população de Mindelo: os Falcões. Segundo M. G. Reis (5 ago. 1933, p.2), o objetivo de tal iniciativa era contribuir para o "levantamento da raça cabo-verdiana ... É uma obra que deve ser coadjuvada pelos bons cabo-verdianos e pelo Estado ...; os resultados far-se-ão sentir: uma nação de espírito levantado, com moral e forte disciplina admirável". De acordo com o informativo oficial do grupo, seu intuito central era mesmo - por meio da articulação entre educação moral, educação cívica e educação física - contribuir para que os jovens se envolvessem com a resolução dos problemas e com a construção de uma colônia forte. ([Noticiário], jan. 1936, p.1).

Em seu livro de memórias, Ramos (2003) relembra com entusiasmo da instituição que, para ele, "deu grande contributo na formação sociocultural da juventude de Cabo Verde" (p.16). De acordo com o autor, os Falcões teriam conseguido:

formar uma grande e unida família cabo-verdiana, afastando de seu seio a maldade, a corrupção, enfim, todos os fatores primordiais da decadência física, moral e intelectual de um povo e constituindo um bloco consistente e indissolúvel, com uma mentalidade livre das misérias horripilantes do século presente (p.53). 
Os Falcões de Cabo Verde seguiam as diretrizes dos Sokols, uma sociedade fundada por Jindrich Fuegner e Miroslav Tyrs, em 1862, em Praga. O movimento surgiu como estratégia de afirmação da cultura checa em um momento em que o país vivia sob a influência do Império austríaco. Com denotado caráter nacionalista e paramilitar, propugnava a ginástica como principal ferramenta de preparação de uma juventude sadia, apta para a condução do país em direção a um futuro mais promissor.

Devemos lembrar que a relação entre a ideia de construção da nação, a necessidade de preparação do cidadão e as propostas de uso da ginástica foi algo comum no decorrer da história, desde pelo menos a sistematização do método alemão, na virada dos séculos XVIII e XIX (Soares, 1994). Os Sokols tinham mesmo uma clara conexão com o pensamento de Friedrich Jahn, um dos artífices das sociedades alemãs de ginástica, as Turnverein. A proposta dos checos também promovia certa leitura da Antiguidade grega, via Romantismo alemão.

O movimento espraiou-se pelo mundo em grande parte pela ação de migrantes do leste europeu, especialmente por ocasião dos dois grandes conflitos mundiais. Um exemplo curioso pode ser encontrado no Brasil: Axel Grael, notório velejador nacional, reconhece a influência de sua avó, Helene Margrete Jelinski que, na Prússia, fora membro da sociedade. Em 1913, em Porto Alegre, chegou a ser fundada a Sociedade Esportiva Sokol.

Núcleos dos Sokols foram instalados em diversos países, notadamente naqueles que encaravam o desafio de consolidar identidades nacionais e a ideia de nação, como a Iugoslávia, a Polônia e os EUA, onde o movimento se difundiu rapidamente e sobrevive até os dias de hoje. Cabe destacar que alguns grupos também se estabeleceram em localidades nas quais havia movimentos nativistas, como na Eslovênia, na Sérvia, na Croácia, na Galícia e na Catalunha, onde em diálogo com a história e a cultura local, adotaram, em maior ou menor grau, a causa da independência. ${ }^{8}$

O movimento também teve repercussões em Portugal. Gomes Santos (diretor do Núcleo de Propaganda Educativa do Governo Salazar), Armando de Aguiar (jornalista do Diário de Notícias) e o general Ferreira Martins (herói português da Primeira Guerra Mundial e membro do Conselho Superior do Exército) chegaram a ir a Praga, em 1932, para acompanhar as atividades de um congresso da sociedade e fazer informes sobre seus congêneres no país da península ibérica (Hanákova, 2006).

Para Jan Klima (2006, p.59), no arquipélago, o movimento implantou-se de forma independente e ainda mais forte do que na metrópole: "Durante sete anos, a colônia portuguesa Cabo Verde foi provavelmente o segundo mais importante local (depois da Checoslováquia) ligado ao movimento Sokol". ${ }^{9}$

Contudo, no meu modo de entender, Klima comete alguns equívocos em sua análise que precisam ser examinados. Para ele, uma das razões do sucesso dos Falcões no arquipélago teria sido a "monótona e pouco inspirada vida dos cabo-verdianos" (2006, p.61). Ao contrário, argumento que sua popularidade, especialmente em Mindelo, teve a ver com o fato de a cidade já possuir tanto uma considerável vida festiva quanto uma antiga tradição de valorização da prática de atividades físicas.

Klima (2006, p.61) afirma ainda que o movimento significou "um esforço preliminar para a emancipação política de Cabo Verde - sentido igual ao que esses elementos tiveram 
na Bohemia depois da Primeira Guerra". Havia, sim, na colônia reivindicações de maior respeito e cuidado por parte da metrópole, o que significava, em certa medida, a solicitação de maior autonomia para as decisões locais. Não creio, todavia, que seja possível considerar tais esforços busca de emancipação política, algo que somente se tornou mais explícito às vésperas da independência, como afirma Anjos (2006, p.72): “A independência de Cabo Verde em 5 de julho de 1975, realizou um objetivo que alguns anos antes só residia na imaginação de relativamente poucos cabo-verdianos".

Assim, parece-me que Klima realizou uma análise apressada da ação dos Falcões. Seus membros investiam, sim, na glorificação de Cabo Verde, mas não com intuitos autonomistas. Pareciam antes mais ligados à linha majoritária de construção identitária caboverdiana naquele momento: convencer Portugal e a própria população local de que o arquipélago, dado o seu grau de civilização, fazia efetivamente parte e contribuía para a glória do Império português.

Os Falcões cabo-verdianos jamais se alinharam a iniciativas independentistas. Sua linha de posicionamento fica clara no primeiro número do boletim da entidade:

Somos indiferentes a politiquices de cada um e só nos interessa tratar de assuntos que redundem benefícios de Cabo Verde, de uma maneira geral. Não maçaremos nossos camaradas com leituras fastidiosas, prosas inúteis ou conversa fiada, mas sim assuntos sensatos, substanciosos, de proveito geral para os Falcões ([Noticiário], jan. 1936, p.2).

Se no decorrer de sua existência houve alguma indisposição com o governo metropolitano, isso se deveu ao enfoque da contribuição para a resolução dos problemas locais. O discurso do movimento tinha sim algo de reformador, de enfrentamento de certos costumes julgados atrasados, mas o diálogo se dava antes localmente do que de fato com a metrópole:

Na Checolosváquia, são os velhos doutores em lei e medicina, cientistas, fisiologistas, que superiormente dirigem os destinos do Sokol. Em Cabo Verde, são os nossos, os pequenos, os sem curso, debaixo do repugnante e vergonhoso indiferentismo dos velhos. Onde está a civilização, nos novos ou nos velhos? Responda o leitor. ([Noticiário], jan. 1936, p.3).

O primeiro núcleo dos Falcões em Cabo Verde foi formado em Mindelo, em 1932, em concorrida cerimônia realizada no Éden Park. O líder da iniciativa foi Júlio Bento de Oliveira, importante personagem da história cabo-verdiana. O movimento logo se espraiou pelo arquipélago; em 1934, chegou a Praia. Estima-se que só em São Vicente a instituição chegou a ter dois mil membros.

Os Falcões eram um movimento muito hierárquico e com uma forte base moral e disciplinar. Seus líderes dividiam-se em: oficiais (de $1^{\underline{a}}, 2^{\underline{a}}$ e $3^{\underline{a}}$ classe), suboficiais (de $1^{\underline{a}}$ e $2^{\underline{a}}$ classe), chefes (de $1^{\underline{a}}$ e $2^{\underline{a}}$ classe) e juniores. Para ascender, o candidato devia fazer provas de comandos, tática, ginástica, esporte, exercício com armas, além de ser submetido a uma análise de sua vida social e moral; para os postos mais altos, havia também testes sobre os principais problemas de Cabo Verde. Os associados eram divididos de acordo com a faixa

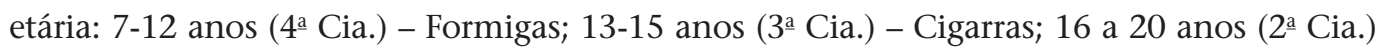
- Falcões; 21-40 Anos (1 ${ }^{\text {a }}$ Cia.) - Falcões. ${ }^{10}$ 
Os que aderissem ao movimento deveriam aprender a marchar, a manejar armas, a fazer uso da telegrafia, a velejar e a assumir o compromisso de praticar diariamente atividades físicas. Para tanto, encontravam-se usualmente na praia da Matiota, na ocasião já chamada de Step, em função de um trampolim instalado em 1908.

Segundo os memorialistas, naquele momento, o balneário já não era tão procurado pela população, uma vez que ali se tornara comum a presença de tubarões, atraídos pelos dejetos jogados no mar pelos navios que atracavam no Porto Grande (Ramos, 2003). Diante desse problema, os membros do grupo teriam confeccionado e instalado na entrada da baía uma rede de arame de aço que impedia a chegada dos animais, o que tornou possível a volta dos banhos de mar e da prática da natação. Com o apoio da Câmara Municipal, por lá construíram uma sede, em 1937.

Não surpreende que aquela parte do litoral tenha ficado conhecida como praia dos Falcões. Depois que a entidade por lá se instalou, a antiga Matiota tornou-se espaço constante de exibições atléticas, jogos esportivos e espetáculos. As paradas públicas e as demonstrações de ginástica do movimento, aliás, eram muito apreciadas pela população e sempre exaltadas pelos jornais:

Nada realmente mais belo do que uma parada de ginástica, os corpos musculosos movendo-se em uma rítmica cadência, os braços em harmoniosos movimentos e o perfeito alinhamento das fileiras, formam um conjunto maravilhoso, soberbo, digno de admiração ([Noticiário], 5 ago. 1933, p.2).

O movimento teve ainda um grupo de teatro, liderado por Antonio Bandeira, que se apresentava com frequência no Éden Park. Suas exibições, que faziam uso de atividades ginásticas, eram muito organizadas e eram um acontecimento bastante aguardado na ilha de São Vicente (Branco, 2004). Branco avalia que ainda que só tenham produzido cerca de quatro ou cinco peças, elas foram fundamentais para despertar o gosto da população e estimular a organização de outros grupos cênicos.

Apesar do sucesso, os rumos da política determinaram, em 1939, o fim dos Falcões em Cabo Verde. O governo metropolitano os extinguiu quando compulsoriamente introduziu no arquipélago outra organização: a Mocidade Portuguesa, criada em 1936, em pleno Estado Novo, com o intuito de promover o amor à pátria por meio do desenvolvimento das capacidades morais e físicas dos jovens. Tal decisão desagradou profundamente tanto os membros do grupo quanto as lideranças locais, ocasionando até mesmo uma resistência inicial à entidade que vinha da metrópole.

Podemos levantar alguns motivos para tentar entender a extinção dos Falcões. Pode ser que a metrópole estivesse se precavendo em função da força do movimento; conhecendo sua matriz nacionalista, pode ter temido alguma iniciativa separatista, medo em grande medida infundado, mas compreensível dada a característica autoritária do regime português. Tais temores cresceriam no pós-Segunda Guerra Mundial, quando eclodiram contestações à sua existência, tanto internas (ainda que, a princípio, tímidas) quanto externas, advindas das novas instituições internacionais ${ }^{11}$ e das colônias, que entrariam em conflito assumido na década de 1960, quando têm início as guerras coloniais na Guiné, em Angola e em Moçambique. 
Nesse momento, aliás, com a descoberta de que alguns clubes eram focos de organização de atividades de contestação (na Guiné, em Angola e em Moçambique), a metrópole percebeu que o esporte não era assim tão alheio à política e ampliou as iniciativas de controle sobre as agremiações esportivas de suas colônias (Bittencourt, 1999).

Vale assinalar que muitos dos Falcões demonstraram, em diferentes oportunidades, senso de liderança. Julio Bento de Oliveira desempenhou um relevante papel político na Câmara de São Vicente. Manuel Rodrigues, um dos líderes do Partido Africano para a Independência da Guiné e de Cabo Verde (PAIGC) na clandestinidade ${ }^{12}$, também declarou que o seu envolvimento com a política teve relação com seu aprendizado com os Falcões (citado em Lopes, 2002). Luís Rendall, que mais tarde tornou-se administrador da ilha, foi mais um dos envolvidos. Baltasar Lopes e outros importantes intelectuais cabo-verdianos demonstraram simpatia pelos Falcões. Mas isso seria suficiente para criar algum temor na metrópole?

Dois acontecimentos permitem perceber melhor a postura dos Falcões. Em 1934, por ocasião de uma crise de abastecimento, um grande número de mindelenses, liderados por Nhô Ambrósio (personagem celebrizado pela literatura local), saqueou os armazéns da alfândega. Segundo Stendall (citado em Lopes, 2002), o movimento foi convocado pelo governo para ajudar a conter a turba. Sua direção, contudo, negou o apoio, argumentando que o grupo não se envolveria em questões políticas. Todavia, quando houve uma crise desencadeada pela extinção do Liceu Infante D. Henrique (1937), os Falcões estiveram entre aqueles que se mobilizaram para reivindicar a sua reabertura (obtida com a criação do Liceu Gil Eanes).

O governo metropolitano, de cariz autoritário, pode ter interpretado tais ações como negativas de alinhamento incondicional (o que era, de fato, verdadeiro). Isso os tornaria suspeitos e perigosos.

No mínimo, havia a disposição de acabar com um concorrente da Mocidade Portuguesa. Foram igualmente extintos os grupos escoteiros das colônias, e por pouco não o foram também os da metrópole, que ainda assim encontraram dificuldades para se manter. ${ }^{13}$ Chegava ao fim a trajetória dos Falcões de Cabo Verde, embora eles jamais se apagassem da memória de muitos cabo-verdianos. ${ }^{14}$

Antes de concluir, devemos destacar um último ponto. Como demonstra José Neves (2009), na metrópole, até a década de 1930, eram intensas as restrições à prática de atividades físicas. Quando esse quadro se altera, mesmo com maior valorização da educação física, persistem as ressalvas ao esporte.

Foi somente na década de 1940 que tanto a ginástica (sueca) quanto o esporte foram definitivamente valorizados, tendo em conta a construção de um sentido de nacionalidade que interessava ao governo autoritário liderado por António Salazar: "O Estado Português reconheceu em boa hora todas as vantagens que poderiam advir da pratica da ginástica e dos desportos e, a exemplo do que já se fazia no estrangeiro, chamou a si a orientação superior da educação física" (Évora, 18 dez. 1955, p.3).

Pelas páginas do periódico oficial da Mocidade Portuguesa, especialmente nos escritos de Virgílio Évora, podemos notar de que modo as atividades físicas passaram a ser consideradas, pela metrópole, uma importante ferramenta de catequização do jovem visando 
obter sua contribuição para a manutenção da grande nação Portugal (o que incluía seus territórios no ultramar). Curiosamente, nesse momento, também os opositores do regime - notadamente os comunistas - já estavam a tecer loas às práticas físicas, considerando seu potencial como agente de mobilização juvenil (Neves, 2009).

A essa altura, como vimos, em Cabo Verde, já havia iniciativas semelhantes, destacandose a ação de duas entidades, o escotismo e os Falcões, expressões de que, de certa forma, a colônia estava sintonizada com o novo papel que as atividades físicas ocupavam no quadro de uma sociedade que se pretendia moderna, articulando-as, como já de costume no cenário internacional, a preocupações com a saúde e a higiene.

\section{Considerações finais}

A Mocidade Portuguesa atuava com dimensões já conhecidas dos cabo-verdianos: a intervenção junto à juventude, por meio de atividades físicas, tendo em vista garantir, literal e metaforicamente, a saúde da nação. Todavia incomodava às lideranças locais a estrutura autoritária da entidade metropolitana, que desconsiderava as tradições da colônia.

Com o lema "Nada contra a Nação, Tudo pela Nação", ao contrário dos outros dois movimentos juvenis, o escotismo e os Falcões que, em Cabo Verde, emergiram de motivações internas, a Mocidade Portuguesa tinha um intuito claramente colonial, concebida como uma das mensageiras da metrópole em territórios africanos: "É um gigante, que une, numa solidariedade inquebrantável, numa fraternidade absoluta, a mocidade portuguesa do continente, das ilhas e do ultramar" (Évora, 18 dez. 1955, p.3).

Se a Mocidade Portuguesa encontrou, a princípio, dificuldades para se implantar no arquipélago - mesmo com todas as ações coercitivas que marcavam sua atuação - nos anos 1950 sua presença já era mais forte. Entre as suas estratégias de intervenção, o esporte ocupava espaço de grande importância:

O desporto tem tido um papel de relevo na vida da Mocidade Portuguesa, porque é sabido que não há nada como este professor, para disciplinar a vontade, para controlar os nervos e para enrijar o corpo, unindo companheiros e raças diferentes, em campos de combate, onde a vitória não significa domínio e derrota, vexame (Évora, 15 jan. 1956, p.6).

No novo cenário, tornou-se ainda mais comum do que antes, em Cabo Verde, a exaltação do esporte como estratégia de formação: "É o complemento da educação moral e intelectual pelo revigoramento físico ... E este revigoramento físico vai ao encontro simultâneo das preocupações do Estado e do sentir geral da massa juvenil de nosso tempo" (Oliveira, 30 ago. 1962, p.6).

Na verdade, movimentos como o escotismo e os Falcões devem ser entendidos em sua ambiguidade. Por um lado, inegavelmente funcionavam como estratégias disciplinares, inclusive no que se refere à propagação de uma determinada visão de saúde. Nesse sentido, serviam a alguns intuitos coloniais, até mesmo por pregar o respeito à hierarquia e às instituições. Por outro lado, fortaleciam elos de autoidentificação e posturas de autoafirmação dos jovens envolvidos, induzindo ao desenvolvimento de laços de solidariedade de 
suma importância para o gestar de um modelo de cidadão mais ativo, crítico, participativo, diferente do que esperava a ação da Mocidade Portuguesa.

Oliveira (1998, p.465) sinaliza que, se havia certos pontos em comum entre a Mocidade Portuguesa e os Falcões, havia também uma diferença significativa:

Não estavam ligados a nenhum partido político nem a nenhum projeto de sociedade. Aceitavam aquela sociedade onde se encontravam, mas procuravam formar um tipo de cidadão ideal, fisicamente bem preparado, com um alto sentido cívico, consciente dos seus deveres e participante na sua sociedade. Era assim uma associação que fugia do figurino fascista.

De qualquer forma, é digno de nota que, em Cabo Verde, esse pequeno e fascinante país, a relação entre saúde, atividades físicas e juventude se tenha estabelecido com tanta frequência e de maneira tão peculiar, sendo mobilizada no âmbito de uma construção identitária que não apontava stricto sensu para a independência, e sim para reivindicação do reconhecimento do crioulo como 'civilizado', digno de participar do Império português nos mesmos patamares que aqueles nascidos na metrópole.

\section{NOTAS}

${ }^{1}$ Um indicador interessante é o número de representações diplomáticas estabelecidas em Mindelo. Segundo Silva (1998), ali havia consulados dos seguintes países: Alemanha, Bélgica, Brasil, Dinamarca, Estados Unidos, Grécia, Inglaterra, Itália, Países Baixos, Uruguai, Rússia, Suécia, Noruega e Turquia.

2 Devemos lembrar que, após cursar a Escola Médico-cirúrgica de Lisboa, o doutor Hopffer se doutorou pela Universidade de Bruxelas. Esteve sempre sintonizado com os avanços da medicina no mundo e ainda que tenha tido problemas com o governo colonial por suas ideias liberais, foi reconhecido pelos serviços prestados a Cabo Verde, tais como a liderança no combate à cólera em 1856-1857. Antes do curso sobre higiene popular oferecido em Cabo Verde, ele organizara experiência semelhante em Lisboa, patrocinada pelo Centro Promotor dos Melhoramentos das Classes Laboriosas, realizada no palácio do conde de Almada, no Rossio.

${ }^{3}$ Para mais informações, ver estudos de Marinho, 1953 e Soares, 1994.

${ }^{4}$ Para mais informações sobre as mudanças na política colonial portuguesa observáveis no final do século XIX, ver Pimenta, 2010.

${ }^{5}$ A primeira edição desse livro é de 1940. A autora refere-se a uma viagem que fizera a Cabo Verde na década de 1930.

${ }^{6}$ A Claridade foi não somente uma das mais importantes revistas da história do arquipélago, como também um dos casos mais notáveis de busca de uma identidade literária em uma colônia portuguesa. Ao seu redor reuniram-se expressivos intelectuais/literatos que assumiram a causa de defesa do povo cabo-verdiano e da afirmação das peculiaridades culturais locais, chegando até mesmo a incluir o cotidiano da colônia em suas obras. Do ponto de vista do estilo, afastaram-se tanto do romantismo quanto do realismo, dialogando com o modernismo brasileiro. Para Graça (2007, p.58): “A caboverdianidade - enquanto atitude filosófico-cultural perante o mundo - surgiu em Barlavento, na Ilha de São Vicente ou São Nicolau, nos finais do século XIX ... Mas a originalidade dessa noção, isso é incontestável, ganha maior configuração e expressão com o movimento claridoso".

${ }^{7}$ Para mais informações sobre o escotismo, ver a página da World Organization of the Scout Movement: http://www.scout.org/front/index.shtml. Sobre as relações entre o esporte e o escotismo, ver Hoberman, 1995. Para o pensamento do fundador do escotismo, ver Powell, 1965.

${ }^{8}$ Por todo o mundo, com configuração distinta, continuam existindo núcleos ligados ao movimento de origem checa, reunidos no International Falcon Movement. Para mais informações, ver http://www.ifmsei.org/.

${ }^{9}$ Nesta e nas demais citações de textos em língua estrangeira, a tradução é livre. 


\begin{abstract}
${ }^{10}$ Para mais informações, ver Estatuto, 1934.
${ }^{11}$ O governo português sofreu diversas pressões de organismos internacionais. A Organização das Nações Unidas, por exemplo, só aceitou o ingresso de Portugal como país-membro em 1955. Buscando responder a tais demandas, a metrópole tomou algumas iniciativas. Por exemplo, os ideólogos do Estado Novo, baseados nas teorias lusotropicalistas de Gilberto Freyre, passaram a defender a peculiaridade da colonização portuguesa, supostamente responsável pela construção de sociedades multirraciais. A revogação, em 1951, do Ato Colonial, um dos sustentáculos da política salazarista e a transformação das colônias em províncias ultramarinas também podem ser entendidas como estratégias de ajuste retórico que reforçava a falsa ideia de um "colonialismo diferente". Para mais informações, ver Castelo, 1999 e Pimenta, 2010.

${ }^{12}$ Para mais informações sobre o PAIGC, ver Lopes, 2002; Pereira, 2003 e Tomás, 2008.

${ }^{13}$ Em Portugal, havia, na ocasião, duas entidades de escoteiros: a Associação dos Escoteiros de Portugal, fundada em 1913, e o Corpo Nacional de Escutismo - Escutismo Católico Português, fundado em 1923. As instituições só não foram fechadas devido a um pedido do arcebispo de Braga, dom Manuel Vieira de Matos. Em outros países que enfrentaram regimes autoritários, o movimento também foi fechado, como na Alemanha de Hitler, na Itália de Mussolini, na Espanha de Franco e na URSS de Stalin. Para mais informações sobre o caso de Portugal, ver Pimentel, 2007 e Rezola, 2007.

${ }^{14}$ Para mais informações sobre o Estado Novo, ver Marques, 1991; Rosas, 1992 e Martinho e Pinto, 2007. Para uma discussão sobre o relacionamento da metrópole com as colônias no âmbito do Estado Novo, ver Castelo, 1999 e Pimenta, 2010. Sobre a Mocidade Portuguesa, ver Pimentel, 2007 e Vieira, 2008.
\end{abstract}

\title{
REFERÊNCIAS
}

ACHER, Maria.

Roteiro do mundo português. Lisboa: Sit. 1950.

ANJOS, José Carlos Gomes dos.

Intelectuais, literatura e poder em Cabo Verde:

lutas de definição da identidade nacional.

Porto Alegre: Editora da UFRGS. 2006.

BARROS, Marília E. Lima.

São Vicente: prosperidade e decadência (1850-

1918). Porto: CEA/UP. 2008.

BITTENCOURT, Marcelo.

Dos jornais às armas: trajectórias da contestação angolana. Lisboa: Veja. 1999.

BRANCO, João.

Nação teatro: história do teatro em Cabo Verde. Praia: Instituto da Biblioteca Nacional e do Livro. 2004.

CASTELO, Cláudia.

"O modo português de estar no mundo": o luso-tropicalismo e a ideologia colonial portuguesa. Porto: Afrontamento. 1999.

ESTATUTO...

Estatuto dos Falcões Portugueses de Cabo Verde. Praia: Imprensa Nacional. 1934.

ÉVORA, Vírgílio.

Nossos princípios. A Mocidade, Praia, ano 1, n.4, p.6. 15 jan. 1956.

ÉVORA, Virgílio.

A Mocidade Portuguesa. A Mocidade, Praia, ano 1, n.2, p.3. 18 dez. 1955.

FERNANDES, Gabriel.

Em busca da nação: notas para uma

reinterpretação do Cabo Verde crioulo. Florianópolis; Praia: Editora da UFSC; Instituto da Biblioteca Nacional e do Livro. 2006.

GRAÇA, Camilo Querido Leitão da.

Cabo Verde: formação e dinâmicas sociais. Praia: IIPC. 2007.

HANÁKOVA, Zuzana.

Relations between Czech Republic and Portugal. Praga: Masaryk University. 2006.

HOBERMAN, John.

Toward a theory of olympic internationalism. Journal of Sport History, Long Beach, v.22, n.1, p.1-37. 1995.

ILIFFE, John.

Os africanos: história de um continente. Lisboa: Terramar. 1999.

KLIMA, Jan.

The cape verdean "sokols" (falcons) in the 1930's. In: Klima, Jan (Ed.). Cabinet of iberoamerican studies: yearbook 2006. Hradec

Kralove: University of Hradec Kralove. p.58-70. 2006.

LIMA, Mesquitela.

A poética de Sérgio Frusoni: uma leitura antropológica. Praia: Instituto de Cultura e Língua Portuguesa; Instituto Cabo-verdiano do Livro e do Disco. 1992.

LOPES, José Vicente.

Cabo Verde: os bastidores da independência. Praia: Spleen Edições. 2002. 
MARINHO, Inezil Penna.

Sistemas e métodos de educação física. São Paulo: Cia. Brasil. 1953.

MARQUES, A. H. de Oliveira (Coord.). Portugal - da Monarquia para a República. Lisboa: Presença. 1991.

MARTINHO, Francisco Carlos Palomanes; PINTO, Antonio Costa (Org.).

O corporativismo em português: Estado, política e sociedade no salazarismo e no varguismo. Rio de Janeiro: Civilização Brasileira. 2007.

MARTIN, Phyllis M.

Leisure and society in colonial Brazzaville.

Cambridge: Cambridge University Press. 1995.

MIRANDA, Augusto.

Saúde. Notícias de Cabo Verde, Mindelo, ano 3, n.57, p.1. 11 ago. 1933.

NEVES, José.

Ler desportivamente Lenine - para a história do comunismo e do desporto em Portugal. Esporte e Sociedade, Niterói, ano 4, n.11, p.1-23. 2009.

[NOTICIÁRIO]

[Noticiário]. Boletim dos Falcões de Cabo Verde, Mindelo, ano 1, n.1, p.1, jan. 1936.

[Noticiário]. Boletim dos Falcões de Cabo Verde, Mindelo, ano 1, n.1, p.2. jan. 1936.

[Noticiário]. Boletim dos Falcões de Cabo Verde, Mindelo, ano 1, n.1, p.3. jan. 1936.

[Noticiário]. Eco de Cabo Verde, Praia, ano 2, n.31, p.3. 22 dez. de 1934.

[Noticiário]. Notícias de Cabo Verde, Mindelo, ano 3, n.56, p.2. 5 ago. 1933.

[Noticiário]. Eco de Cabo Verde, Praia, ano 1, n.6, p.1. 15 jul. de 1933.

[Noticiário]. Eco de Cabo Verde, Praia, ano 1, n.6, p.7. 15 jul. de 1933.

[Noticiário]. O Futuro de Cabo Verde, Mindelo, ano 1, n.30, p.3. 20 nov. 1913.

[Noticiário]. Independente, Praia, ano 1, n.15, p.2. 12 ago. 1912 .

OLIVEIRA, João Nobre de.

A imprensa cabo-verdiana: 1820-1975. Macau: Fundação Macau. 1998.

OLIVEIRA, Marques.

A juventude e o desporto. Arquipélago, Praia, ano 1, n.2, p.6. 30 ago. 1962.

PEREIRA, Aristides.

O meu testemunho: uma luta, um partido, dois países. Lisboa: Notícias. 2003.
PIMENTA, Fernando Tavares.

Portugal e o século XX: Estado-Império e descolonização (1890-1975). Lisboa: Afrontamento. 2010.

PIMENTEL, Irene Flunser.

Mocidade portuguesa feminina. Lisboa: A Esfera dos Livros. 2007.

POWELL, Baden.

Caminho para o sucesso. Rio de Janeiro: Escoteira. 1965.

RAMOS, Manuel Nascimento.

Mindelo d'outrora. Mindelo: Gráfica do Mindelo. 2003.

REIS, M. G.

Os Falcões. Notícias de Cabo Verde, Praia, ano 3, n.56, p.2. 5 ago. 1933.

REZOLA, Maria Inácia.

A Igreja católica portuguesa e a consolidação do salazarismo. In: Martinho, Francisco Carlos Palomanes; Pinto, Antonio Costa (Org.).

O corporativismo em português: Estado, política e sociedade no salazarismo e no varguismo.

Rio de Janeiro: Civilização Brasileira. p.239-172. 2007.

ROSAS, Fernando (Coord.).

Portugal e o Estado Novo. Lisboa: Presença. 1992.

SAIAL, Joaquim.

Aspectos da biografia de Sérgio Frusoni.

Disponível em: http://liberal.sapo.cv/

noticia.asp?idEdicao $=64 \& i d=4035 \& i$

dSeccao $=527 \&$ Action $=$ noticia

Acesso em: 21 mar. 2010. 2006.

SILVA, Adriano Duarte.

Cultura física e cultura literária. Praia: Imprensa Nacional de Cabo Verde. 1924.

SILVA, Antonio Correia e.

Espaços urbanos de Cabo Verde: o tempo das cidades-porto. Praia; Mindelo: Centro Cultural Português. 2000.

SILVA, Antonio Correia e.

Nos tempos do Porto Grande do Mindelo. Lisboa: CNCDP. 1998.

SILVA, Antonio Correia e; COHEN, Zelinda. O sistema colonial português e a gênese do movimento protonacionalista em Cabo Verde. In: Pereira, Aristides. O meu testemunho: uma luta, um partido, dois países. Lisboa: Notícias. p.38-70. 2003.

SILVA, Luís.

Do cinema em Cabo Verde: contribuição para sua história (I). Disponível em: http:// www.islasdecaboverde.com.ar/san_vicente/ eden_park/6_do_cinema_em_cabo_verde_ contribuicao_para_sua_historia_(I).htm. Acesso em: 3 maio 2010. 2006. 
SOARES, Carmen Lúcia.

Educação Física: raízes europeias e Brasil. Campinas: Autores Associados. 1994.

TOMÁs, Antônio.

O fazedor de utopias: uma biografia de Amílcar Cabral. Praia: Spleen. 2008.
VIEIRA, Joaquim.

Mocidade portuguesa. Lisboa: A Esfera dos Livros. 2008.

\section{$\rightarrow \rightarrow \rightarrow<<$}

